\title{
LA ERÓTICA DE LA MUERTE EN UN PERSONAJE CLARINIANO: ÁNGEL CUERVO. ESTUDIO DE UNA PASIÓN
}

\author{
Ángeles EZAMA GIL \\ Universidad de Zaragoza
}

\begin{abstract}
Fue entonces, en efecto, cuando empezó a escribir su Confesión, [...] que era el relato de su lucha íntima con la pasión que fue su vida [...] Esta confesión se hacía dirigida a su hija, pero tan penetrado estaba él del profundo valor trágico de su vida de pasión y de la pasión de su vida, que acariciaba la esperanza de que un día su hija o sus nietos la dieran al mundo, para que éste se sobrecogiera de admiración y de espanto (M. de Unamuno, Abel Sánchez. Una historia de pasión, pág. 147).
\end{abstract}

La novelita clariniana Cuervo se publica por vez primera en el diario madrileño La Justicia los días 1, 2 y 3 de Enero de 1888 (Botrel y Blanquat, pág. 56); con posterioridad aparece en las páginas del "Suplemento de ciencias, literatura y artes" de La Correspondencia de España los días 9, 16, 30 de Noviembre y 21 de Diciembre de 1890 . Por fin, en 1892 se publica en volumen junto con Doña Berta y Superchería en la editorial de Fernando Fe.

La primera edición en volumen incluye las novelitas por este orden: Doña Berta, Cuervo, Superchería, orden que se respeta en la edición publicada en 1929 por la Editorial Renacimiento, así como en la de 1943 con prólogo de Ramón Pérez de Ayala. La edición de Taurus de 1970 altera este orden (Superchería, Cuervo, Doña Berta), contraviniendo así las indicaciones del propio escritor al respecto, el cual, en carta a su editor, le manifiesta su intención de publicar un volumen de tres "nouvelles" con Doña Berta al frente, y destacada en el título sobre las otras dos: "Deseo que en la portada se lea Doña Berta con letras mayores y después con otras bastante más pequeñas Cuervo-Superchería" (Botrel y Blanquat, pág. 6).

Cuervo es el relato más breve del volumen de 1892 y también el que menor atención crítica ha recibido. Además, las valoraciones de que ha sido objeto 
han tendido, más que a subrayar sus valores intrínsecos, su cualidad de "producción extraña" en el conjunto de la narrativa clariniana. Así, Ricardo Gullón la considera una novela fracasada, porque Clarín "para crear aladamente necesitaba sentir por los personajes una corriente de simpatía que en el caso de Cuervo no llegó a experimentar".

Por su parte, Sobejano (pp. 94-96) la considera una novela heterodoxa, "producto extraño o único" entre las otras dos que integran el volumen de 1892; Laura de los Ríos (pág. 89) dice de ella que es "una obra extraña, difícil de clasificar"; y José M. González Herrán (1987, pág. 86) la conceptúa de "rara avis en el corpus narrativo de Clarín".

Estas más que cuestionables apreciaciones sobre el relato son el resultado de un desenfoque en su valoración: el juicio sobre Cuervo se hace en términos relativos, mediante su cotejo con Doña Berta y Superchería, relatos cuya técnica compositiva es muy distinta, como ya lo hizo notar Ramón Pérez de Ayala (pág. 23): "Aquí tienes, lector, un libro de Clarín. Contiene tres novelas cortas. Mejor dicho, dos novelas cortas (Doña Berta y Superchería) y otra obrilla, de cortas dimensiones, Cuervo, que pertenece a la línea sucesoria de los Caracteres dè Teofrasto".

Asimismo, se habla en términos relativos cuando se considera Cuervo como relato inacabado, proyecto o esbozo de personajes para una novela de mayor envergadura. Además, las apreciaciones a este respecto son meras hipótesis, puesto que no disponemos de otros datos sobre este relato que los que nos proporciona el mismo texto; por ello, aventurar suposiciones sobre su condición de relato inacabado resulta, cuando menos, arriesgado.

Hay aún otro aspecto compositivo que hace de Cuervo un relato "atípico" frente a los otros dos del volumen; mientras que en Doña Berta y Superchería el narrador cuenta una experiencia singular que afecta de modo peculiar al personaje en un momento determinado de su vida, en Cuervo el narrador relata una vez un ritual que se repite con frecuencia en la vida del personaje, adoptando ese carácter genérico de "imitación de lo universal", que Leonardo Romero (pág. 256) señala como uno de los ingredientes esenciales del tipo costumbrista. $Y$, en efecto, este relato clariniano es un ejemplo perfecto para ilustrar las dificultades de deslindar dos géneros tan próximos como el cuento y el artículo de costumbres ${ }^{1}$, como muy acertadamente intuyó Mariano Baquero Goyanes (1949b, pp. 95-102). Textos igualmente problemáticos en su conceptuación genérica los encontramos entre los escritores contemporáneos, v. gr. en cuentos de Joaquín Dicenta como Los blanqueros y El maquinista o de Juan Ochoa como Un genio y Rodríguez Chanchullo.

1. La influencia del costumbrismo en la aparición y desarrollo de la novela realista es uno de los aspectos más discutidos en la crítica sobre el tema, en particular desde el trabajo de José Fernández Montesinos. La vinculación entre las colecciones de tipos y escenas y la obra narrativa de escritores como Alarcón, Valera, Galdós o Blasco Ibáñez resulta incuestionable para Enrique Rubio (1983 y 1988). 
La valoración ajustada de Cuervo implica un cambio en los supuestos desde los que habitualmente ha sido estudiado el relato. Para ello habremos de comenzar por intentar dar una explicación a la más que evidente disfunción estructural entre anécdota narrativa y caracterización del personaje.

\section{La anécdota narrativa.}

La anécdota narrativa ilustra el ambiente de resistencia que acompaña, en la España del momento, los intentos de reforma en el terreno de la "higiene pública"2. Los numerosos tratados elaborados por higienistas como respuesta a este problema social someten invariablemente a consideración el tema del agua, tanto en sus aspectos beneficiosos como en los perjudiciales para la salud; el estancamiento (Pedro Felipe Monlau, 1847, pp. 174-182) y la contaminación de las aguas (José G. Richardson, pp. 83-89) son los causantes de estos últimos.

El relato clariniano asume este estado de opinión en torno al tema de la higiene. El pueblo que sirve de marco a los personajes se llama, y no por casualidad, Laguna, está rodeado de prados pantanosos, es insalubre, y sus habitantes responden al "toponímico" de lagunenses o paludenses 3 ; entre ellos la mortalidad es muy elevada (Pedro Felipe Monlau, 1847, pág. 176). EI médico higienista $\mathrm{D}$. Torcuato Resma, encargado de velar por la higiene pública, encuentra la causa de tan elevada mortalidad en la contaminación de las aguas:

De todo le echa la culpa al río, y dice que por el río puede venir la peste, y que se filtran por las capas de la tierra no sé qué diablos de animalejos que nos envenenan; y cita ejemplos de cosas que pasaron allá en tierras de franchutes; tal como el haber echado entre el estiércol de un corral no sé qué sustancias que solitas, pian, pianito, vinieron por debajo de tierra para

2. La tan debatida cuestión de la higiene pública no alcanza su fundamento científico hasta el siglo XIX (AA.VV.; Mercedes Granjel, pp. 17-74): entre 1848 y 1914 la higiene se constituye como ciencia y quedan definitivamente resueltas las doctrinas del contagio con las investigaciones sobre microbiología. El método que sirve de base a esta ciencia en una primera fase es el de la estadística demográfico-sanitaria, de cuya utilización dan fe, entre otros, los trabajos de A. Quetelet (conocido por su concepto de "l'homme moyen").

La influencia inglesa, pionera en las investigaciones sobre el tema, se hizo sentir en varios países, entre ellos España, donde destaca la labor de Pedro Felipe Monlau, sin duda el más brillante de los higienistas españoles $(1846,1847)$.

3. Cf. P.F. Monlau, 1847, ed. 1871, pág. 175:

Tanto y más que las corrientes deben llamar la atención las aguas estancadas, generalmente impuras y funestas para la salud de los hombres y la salubridad del territorio. [...] Excede a todo cálculo el número de víctimas que en todo el Globo, y especialmente en nuestra misma España, han sacrificado, y están sacrificando anualmente, las aguas encharcadas [...] Importa sobremanera, pues, dar curso veloz a las aguas impuras o estancadas, desaguar y secar los pantanos y lagunas perjudiciales [...] Al efecto se estudiará el respectivo modo de formación de cada Laguna, pantano o charca, la naturaleza de sus aguas, de su población vegetal y animal, de su fondo, de sus efluvios y de los efectos de éstos, etc. 
envenenar el río y después hacer que reventaran los vecinos de no sé qué ciudad ribereña.. (pág. 125) ${ }^{4}$.

Intenta paliar sus efectos recomendando higiene, recurriendo a las estadísticas demográficas, las tablas de mortalidad y la doctrina del término medio de Quetelet, y realizando observaciones "en el cementerio y en el hospital, y en la malatería y en las viviendas pobres, y hasta en la ropa de los vecinos honrados" (pág. 112).

Las alusiones a la falta de limpieza del pueblo en el cuidado del entorno urbano y del cuerpo (pág. 129), y de Cuervo en el vestido ${ }^{5}$, se orientan en esta misma dirección.

El problema de la higiene, no obstante, no parece afectar solamente al aspecto "material" de la vida de los lagunenses; es evidente que en Cuervo la higiene "moral" manifiesta en el peculiar estado anímico de los habitantes de Laguna (cuya alegría resulta provervial), así como en la "limpieza" que define la concepción de la muerte en Cuervo, no constituyen sino una respuesta ( ¿antídoto tal vez?), eficaz paliativo moral con el que hacer frente a las funestas consecuencias derivadas de la falta de salubridad.

\section{El retrato del personaje.}

Pero el desconcierto que esta novelita produce en el lector no proviene de la anécdota en sí, meramente circunstancial, sino de la reducción de ésta, elemento obligado en el relato breve tradicional (v. gr. Doña Berta y Superchería), al mínimo, y en la intensificación extrema de la parte dedicada al retrato del personaje, retrato "moral" que no es, ni mucho menos, único en la narrativa

4. En adelante citaré la novelita por la edición de 1892, indicando únicamente el título y la páginas.

Cf. José G. Richardson, pp. 83-89:

Cuando la lluvia cae sobre la tierra, una parte llena los estanques y va a engrosar los ríos; pero la parte mayor filtra a través del suelo, y después de muchas horas, o de muchos días, pasando por pequeños agujeros, se concentra en nuestros pozos. En el curso de su viaje hacia el centro de la tierra, disuelve, según dejamos dicho, numerosas substancias minerales [...] con respecto a las materias animales que encuentra con demasiada frecuencia en su camino, [...] pueden cambiar un agua potable en un veneno oculto y lento, $\mathrm{o}$ en un agente de destrucción inmediata.

5. "Don Ángel vestía de negro y enseñaba apenas un centímetro de cuello de camisa, y este poco no muy blanco" (Cuervo, pp. 128 - 129). Nuestro personaje, además usa "sombrero de copa de forma anticuada, algo grasiento" (Cuervo, pág. 119); en 1870 el Dr. Dulcamera afirma en su artículo que el sombrero de copa es antihigiénico.

6. Por estos años se publican algunos ensayos sobre la "higiene de las pasiones", como los de D. Foy y J.B.F. Descuret. Además, en los tratados de "higiene privada" se suele dedicar un capítulo a la higiene de las pasiones; v.gr. P.F. Monlau trata en sus Elementos de higiene privada de las sensaciones internas y de las pasiones, y señala que "el placer y el dolor son indispensables para la existencia y deben servirnos igualmente de reglas de higiene (1846, pág. 334). 
clariniana (vid. v. gr. relatos como El hombre de los estrenos -Pipá-, Un candidato —Palique - o Don Urbano - Cuentos morales; Mariano Baquero Goyanes, 1946, pág. 142 y 1949a, pp. 162 - 164), y que se explica perfectamente a la luz del prólogo que Clarín escribe para su colección de Cuentos morales (pp. 5-6):

Aun reduciendo el significado de moral a la virtud que una cosa puede tener para moralizar a los que cabe que sean seres morales (los individuos racionales), diré que mis cuentos no son morales en tal concepto. Los llamo así porque en ellos predomina la atención del autor a los fenómenos de la conducta libre, a la psicología de las acciones intencionadas. No es lo principal, en la mayor parte de estas invenciones mías, la descripción del mundo exterior ni la narración interesante de vicisitudes históricas, sociales, sino el hombre interior, su pensamiento, su sentir, su voluntad.

A partir de la apreciación de R. Pérez de Ayala en el prólogo a la edición de 1943 de Doña Berta. Cuervo, Superchería, todos los críticos han venido reiterando la adscripción de Cuervo a la línea de literatura moral que se inicia con los Caracteres de Teofrasto (s. IV a.c.), y después de numerosas imitaciones, culmina en el siglo XVII con Les caractères de La Bruyère (1688).

En los estudios sobre la moral confluyen, desde mediados del siglo XVIII, reflexiones filosóficas (David Hume, Charles Letourneau, Mme de Staël), pseudo-ciencias como la fisiognómica (Jean-Gaspard Lavater; Ramón Carnicer, pp. 267-272), investigaciones empíricas que cifran su objetivo en el análisis de la interrelación entre el comportamiento y carácter del ser humano y su fisiología", y manifestaciones literarias como la moda de las "fisiologías" (José Fernández Montesinos, pp. 95-106), estrechamente ligada a la aparición y desarrollo del costumbrismo.

Precisamente un tipo costumbrista, el del "agente fúnebre", de la colección Los españoles de ogaño (Tomás Luceño y Becerra), podría muy bien hallarse en la base de la configuración de Cuervo. Este tipo, perteneciente por lo general a la clase pobre del pueblo, suele vestir "chaqueta larga, chaleco, pantalón y corbata negros, sin omitir nunca el sombrero de copa con grasa ", y "carece de todo sentido de humanidad", considerándose feliz únicamente cuando se muere mucha gente; entra en las casas donde alguien se muere con aspecto risueño y complaciente, haciendo mucho ruido, y se ocupa de todas las circustancias que rodean a la muerte, No obstante, el personaje clariniano supera el aspecto puramente comercial del tipo citado al convertir la vivencia de la muerte en una pasión.

7. La frenología del Dr. Gall, ampliamente conocida en España por medio de traducciones, tratados de divulgación, manuales, revistas, y sobre todo gracias a la obra de Mariano Cubí y Soler, autor de varios trabajos sobre el tema y al que se considera el introductor de esta ciencia en España (Ramón Carnicer), y, posteriormente, las teorías del Dr. Lombroso (Luis Maristany, 1973, 1983); estas últimas ejercen un influjo indudable entre los escritores españoles (Lily Litvak, José Luis y Mariano Peset, Benito Mariano Andrade; Luis Maristany, 1983, pp. 373-381). 
Situado en la línea de todas estas consideraciones sobre la moral, Cuervo no constituye sino el análisis minucioso de un carácter, la anatomía de una pasión. Clarín parece complacerse en encarnar en sus personajes clericales (o seudo-clericales, como es el caso de Cuervo) pasiones avasalladoras; la profundamente sensual de Fermín de Pas, primero hacia Vetusta (su pasión y su presa) y luego hacia Ana Ozores, la del cura de Vericueto (protagonista del cuento de este título) hacia el juego o el amor platónico de Juan de Dios ("El Señor") por Rosario. Ángel Cuervo encarna la pasión por la vida frente a la muerte ajena, el profundo deleite sensual, individual y egoísta del ser humano que afirma su placer de vivir mientras otros se disgregan en la nada.

Cuervo parece un personaje salido de uno de los sermones del Magistral. Este, sin duda uno de los más espléndidos estudios de carácter perfilados en la narrativa clariniana, es además un aficionado a los estudios morales (Clarín, 1884, ed. 1984, pp. 450-453): lee con deleite los Caracteres de la Bruyère ${ }^{8}, E l$ Criterio de Balmes, y novelas contemporáneas que toma como punto de partida para el análisis de costumbres y temperamentos; sobre estos datos, cotejados con los de su experiencia personal, elabora sus sermones, cuyo tema preferido son los vicios y virtudes y sus consecuencias. De suerte que De Pas pinta el tipo del avaro, el del borracho, el del embustero, el del jugador, el del soberbio, el del envidioso y el del joven lujurioso, sin duda "su estudio más acabado", que cuenta con un perfecto exponente en el párroco de Contracayes presentado en el capítulo XII (Clarín, 1884, ed. 1984, pp. 460-464) de la novela.

Un cuasi-clérigo semejante en su apariencia y en su pasión al cura de Contracayes, transformada esta última en lujuria vital que aleja toda idea de destrucción en las proximidades de la muerte, es Cuervo, retrato de un carácter moral no aislado ni en la obra clariniana, como hemos visto, ni en el relato corto contemporáneo (v. gr. en los cuentos de J. O. Picón).

La ocupación habitual de Cuervo es la muerte, que comienza siendo una "necesidad e industria lícita, y en parte afición ingénita" y se convierte luego en "pasión viva, vocación irresistible" (cap. III) que el personaje llega a elevar a categoría de arte (cap. VII), por medio del cual ejerce su dominio sobre los lagunenses. Su concepción de la muerte es esencialmente "limpia" (Cuervo, pág. 128 ), vital (resumida en el "ergo vivamus" del capítulo $X$ ) y, por lo mismo, profundamente sensual, teñida de una voluptuosidad extrema que invita al goce de los sentidos (cap. VIII):

Entonces sí que gozaba de veras don Ángel, sin malicia alguna y sin algazara, que sería monstruosa profanación; gozaba sin darse cuenta de ello, saboreando el placer recóndito, que era el alma, la más profunda médula de

8. La obra del moralista francés hubo de ser bien conocida por los escritores decimonónicos, ya que de ella se publicaron, a lo largo del pasado siglo, al menos cinco ediciones (Robert Garapon, pág. XLV). 
toda esta pasión invencible de nuestro hombre; un placer de que no podía acusarse, porque lo sentía sin reconocer su naturaleza; y consistía en saborear la vida, la salud, el aguardiente, el tabaco, la buena conversación (pág. 134)

El vitalismo de que se nutre el personaje clariniano, afirmación de salud pletórica frente a la muerte ajena, no es sino un sentimiento egoísta, profundamente enraizado en el ser humano, y que surge en la narrativa clariniana como respuesta contra lo excesivamente racional y científico; Mariano Baquero Goyanes ya señalaba en 1949 que Clarín propone en algunos de sus cuentos (v. gr. Doctor Sutilis, La mosca sabia, El gallo de Sócrates) "un vitalismo que, en ocasiones, llega a lo pánico y primario" (1949a, pp. 10-11; 1952, pp. 199 y ss.).

Esta vivencia "apasionada" de la muerte se explica perfectamente a la luz del tratado de Mme de Staël; en el capítulo 5 de la lección 1 trata su autora sobre pasiones como el juego, la avaricia y la ebriedad (pp. 179-189), que caracteriza como "sensations égoïstes", cuya única ventaja cifra en "l'agitation que suspend le sentiment et la pensée; elles donnent une sorte de personnalité matérielle, qui part de soi pour revenir à soi, et fait tripompher ce qu'il y a d'animal dans l'homme sur le reste de sa nature" (pág. 180). Para Mme de Staël la pasión que mejor resume la necesidad de emoción es el juego, y la que satisface del modo más acertado el egoísmo, la avaricia. La pasión por la muerte que embarga a nuestro personaje parece resumirlas ambas.

La carga de sensualidad de que este vitalismo dota al relato nos permite hablar de una auténtica "erótica de la muerte"; revulsivos como la comida, la bebida, el sexo, la naturaleza o la salud se esgrimen como defensa frente a la aniquilación vital ${ }^{10}$, todos ellos acompañados por un derroche de sensaciones auditivas del que forman parte desde el murmullo de las conversaciones y del coro fúnebre, pasando por el orquestado concierto de los pucheros en la cocina, hasta el sonido concertado de la naturaleza.

En el momento supremo del goce sobre la muerte Cuervo encuentra un correlato de su pasión en Antón el Bobo, personaje de mucho menor relieve que aquél pero que constituye un reflejo suyo ${ }^{11}$, como el propio Cuervo reconoce

9. Tal "erótica de la muerte" únicamente es parangonable, en la narrativa clariniana, con la "erótica del poder" experimentada por Fermín de Pas en el capítulo I de La Regenta, mientras escudriña su presa, Vetusta, desde lo alto de la torre de la catedral, o con la voluptuosidad que invade al Magistral en el capítulo XXI al contacto con el recuerdo y la presencia de Ana. Voluptuosidad esta última cuyo símbolo explícito es la rosa: el capullo que De Pas deshoja y muerde con fruición en el parque tras leer la carta de Ana; los capullos de mujer, rosas propiedad del Magistral que son Jas niñas de la Catequesis, y la rosa de Alejandría que Ana deposita en manos de De Pas mientras pasean por el parque.

10. La enumeración sustantiva, suma de elementos aliados de la vida frente a la muerte, es un recurso expresivo de primer orden al servicio de esta sensualidad: "tenía el instinto seguro de los acontecimientos más a propósito para recordar la vida, la actividad, la salud, la fuerza, el movimiento, todo lo contrario de la muerte (Cuervo, pág. 141).

11. El gusto por la "duplicación" de personajes es una constante del volumen de novelas cortas de 1892; en Doña Berta Sabel es un reflejo de Berta, en Superchería Alcázar lo es de Nicolás 
(Cuervo, pág. 150). Antón juega un papel muy preciso en ese entramado casi teatral que rodea al aparato de la muerte: el de simple de sainete (Antón es acogido en los banquetes fúnebres "como un sainete muy oportuno", pág. 154, que admira "los elementos pintorescos y dramáticos de los entierros", pág. 150). Por su parte, Cuervo transforma el escenario de la muerte, a fin de que desaparezcan todos los vestigios de ésta, como el mejor tramoyista; y a los pocos momentos nadie reconocía la habitación en que había resonado un estertor horas antes (pág. 143); protagoniza una "escena, o serie de escenas, a solas con el que quedaba, con la viuda, con el hijo..." (pág. 143) ${ }^{12}$, y dispone todo lo necesario para el banquete fúnebre; el aspecto teatral de su arte encuentra su máxima expresión en el cortejo que acompaña al muerto al cementerio:

Delante la cruz y los ciriales; detrás la caja, y luego, en dos filas, el coro de la muerte, el coro trágico, que calla a ratos, mientras habla el misterio de ultratumba allí dentro, en la caja, sin que lo oigan los del coro; como en el palacio de Agamenón, mientras Orestes asesina a Egisto no se oye nada... Y vuelve el coro a cantar, a cantar los terrores de la muerte; terrores de que no habla la letra, a que nadie atiende, pero de que hablan las voces cavernosas, el canto llano, el aparato fúnebre. (pág. 157).

El sentimiento vital ante la muerte asumido por Cuervo y Antón resume sin duda una inquietud personal del propio Alas, entregado, a partir de 1890, a la búsqueda de una religiosidad auténtica (Yvan Lissorgues, pp. 303-365), apartada de los ritos vacíos de la religión cristiana (Ibíd. pp. 116-130), una religiosidad ejemplar en la que exista una coherencia entre las ideas y los hechos. Tal vez Cuervo constituya un primer paso en esta dirección, pues si bien es cierto que a través del personaje denuncia el narrador la ignorancia de los rezos memorizados y la superficialidad de una religión reducida al puro rito externo, apela a la vez a un sentimiento religioso primitivo, pero auténtico, de marcado carácter pagano.

El rito mortuorio asumido por Cuervo reproduce, a buen seguro, la peculiar mitología asturiana de la muerte; a este respecto resulta ilustrativo repasar el ensayo del folclorista Constantino Cabal La mitología asturiana. Los dioses de la Muerte, en el que encontramos documentadas las circunstancias más notables que rodean la celebración de la muerte en Asturias, algunas de las cuales

Serrano y Tomassuccio de Caterina Porena. Estos personajes, que constituyen un desdoblamiento desdibujado del protagonista, son como un espejo en el que el personaje principal se refleja y gracias al cual destaca en el relato por su mayor relieve frente al otro.

12. En estas escenas Cuervo consigue ahuyentar el fantasma de la muerte en los parientes del difunto: Cuervo se daba arte para irritar en la viuda el sentido íntimo de la salud, del bienestar que busca expansión [...] En adelante Cuervo, a pesar de su aspecto poco pulcro, casi fúnebre, representaba la vida, el placer futuro, la efectividad de la dicha saboreada poco a poco, con deleite [...] Don Ángel venía a ser la Celestina de estas relaciones ilícitas entre la viuda y la infidelidad futura, el amor repuesto, la voluptuosidad aplazada (Cuervo, pp. 144-145; cf. R. de Mesonero Romanos, pág. 122). 
pueden identificarse en Cuervo: la "noche del aguardiente" (Cabal, pp. 73-74; cf. Cuervo, pp. 133-138), el acompañamiento del cadáver por las lloronas (Cabal, pág. 75; cf. Cuervo, pág. 154), el convite tras el entierro (Cabal, pp. 7779; cf. Cuervo, cap. XI), la creencia en una vida bajo tierra (Cabal, pp. 24-31; cf. Cuervo, pp. 132-133), la metempsícosis (Cabal, pp. 31-33; Cuervo, p. 146) incluso.

En la vivencia de la muerte que Cuervo realiza se distinguen dos partes: el rito social y el rito personal (Cuervo, pág. 47); esta distinción condiciona la estructuración del relato, porque el narrador, que apela al orden de los hechos narrados al final del capítulo VI (Cuervo, pág. 129), altera voluntariamente el orden de exposición de los sucesos cuando se refiere al rito mortuorio, comentando primero el rito social (cap. VII: relación con los moribundos; cap. VIII: "La noche del aguardiente"; cap. XI: la vuelta del entierro; cap. X: el consuelo a los parientes) y posponiendo el personal hasta el último capítulo (cap. XI: asistencia al entierro $\left.{ }^{13}\right)$.

De este modo, el capítulo XI se convierte en el momento culminante de la narración, en esa escena en que Cuervo y Antón, escuchando la gozosa letra del "Benedictus", se deleitan "extáticamente" en la contemplación de una naturaleza que anega la muerte en vida, tal vez respondiendo al tono de la antífona que acompaña habitualmente, en el ritual romano, al canto citado: "Ego sum resurrectio et vita". Este final "trascendente", en apariencia inconcluso, es el cierre perfecto del relato porque representa la culminación de la pasión del personaje ${ }^{i 4}$ :

Y en tanto, los pájaros en los setos de la calleja y en los árboles de la huerta, trinan, gorjean, silban y pían; las nubes corren silenciosas, solemnes, por el azul del cielo; la brisa cuchichea y retoza con las mismísimas ropas talares del acompañamiento de la muerte; y Antón y Cuervo, en el colmo de un deliquio, oyen como extáticos, como en ensueños, el run run del Benedictus, los sonidos dulces y misteriosos de la naturaleza, que, como ellos, ve pasar la muerte, sin comprenderla, sin profanarla, sin insultarla, sin temerla, como albergándola en su seno, y haciéndola desaparecer cual una hoja seca en un torrente, entre las olas de vida que derrama el sol, que esparce el viento y de que se empapa la tierra. (pág. 158)

13. El banquete fúnebre que se describe en este capítulo remite al de otro cuento clariniano, Manín de Pepa José, incluido en la colección póstuma Doctor Sutilis.

14. Tal vez pueda detectarse en este final un influjo del también "trascendente" cierre del relato flaubertiano de 1877 Un coeur simple:

Une vapeur d'azur monta dans la chambre de Félicité. Elle avança les narines, en la humant avec une sensualité mystique, puis ferma les paupières. Ses lèvres souriaient. Les mouvements de son coeur se ralentirent un à un, plus vagues chaque fois, plus doux, comme une fontaine s'épuise, comme un écho disparaît; et, quand elle exhala son dernier souffle, elle crut voir, dans les cieux entrouverts, un perroquet gigantesque, planant au-dessus de sa tête (Flaubert, pág. 83). 


\section{BIBLIOGRAFÍA}

AA.VV. 1974 Historia universal de la medicina, coordinada por Pedro Laín Entralgo, Barcelona, Salvat Editores, vols. V (Ilustración y romanticismo) pp. 143-151 y 344-345, y VI (Positivismo) pp. 175-192, 363-370.

ANDRADE, Benito Mariano. 1896. La antropología criminal y la novela naturalista, Madrid, Est. Tip. Sucs. de Rivadeneyra.

BAQUERO GOYANES, Mariano. 1946. "Clarín, novelista olvidado", Revista de la Universidad de Oviedo, pp. 137-145.

- 1949a. "Clarín, creador del cuento español", Cuadernos de Literatura, V, pp. 145-169.

- 1949b. El cuento español en el siglo XIX, Madrid, C.S.I.C.

- 1952. "Exaltación de lo vital en La Regenta", Archivum, II, pp. 189-219.

BOTREL, Jean-François y Josette BLANQUAT. 1981. Clarín y sus editores, 65 cartas inéditas de Leopoldo Alas a Fernando Fe y Manuel Fernández Lasanta, 1884-1893, Rennes, Université de Haute Bretagne.

CABAL, Constantino. 1925. La mitología asturiana, Los dioses de la muerte. Madrid, Imp. Juan Pueyo.

CARNICER, Ramón 1969. Entre la ciencia y la magia, Mariano Cubí. En torno al siglo XIX español, Barcelona, Editorial Seix-Barral.

CLARÍN. 1892. Doña Berta, Cuervo, Superchería, Madrid, Fernando Fe.

- (1875) 1972 “El rito”, El Solfeo, nº. 175, 23-II-1875, en J.F. Botrel, Preludios de Clarín, Oviedo, Instituto de Estudios Asturianos, pp. 50-51.

— (1896) 1982. "Prólogo", Cuentos morales, Madrid Bruguera, pp. 5-7.

- (1884) 1984. La Regenta, ed. de Gonzalo Sobejano, Madrid, Castalia, I.

DESCURET, J.B.F. 1889. La medicina de las pasiones o las pasiones consideradas con respecto a las enfermedades, a las leyes y a la religión, traduc. por Pedro Felipe Monlau, $3^{\text {a }}$ edición revisada, corregida y aumentada con adiciones del traductor, Barcelona, Impta. y Liba. Religiosa y Científica.

DICENTA, Joaquín. 1897. Los blanqueros, El País, 15 de Diciembre de 1897.

- 1898. El maquinista, El País, 1 de Enero de 1898.

DR. DULCAMERA. 1870. "La higiene y la moda. Los sombreros", La América, n. 8, 28-IIV-1870, pp. 3-4.

FERNÁNDEZ MONTESINOS, José. (1959) 1983. Costumbrismo y novela. Ensayo sobre el redescubrimiento de la realidad española, 5a edición, Madrid, Castalia.

FLAUBERT, Gustave. (1877) 1965. "Un coeur simple" (1877) en Trois contes, París, Flammarion. 
FOY, D. 1845. Manual de higiene o estudio de los medios oportunos para conservar la salud y perfeccionar lo físico y lo moral del hombre, Madrid, I. Boix.

GARAPON, Robert. 1962. "Introduction" a La Bruyère, LES CARACTERES de Théophraste traduits du grec avec LES CARACTERES ou les Moeurs de ce siécle, Paris, Editions Garnier Frères.

GONZÁLEZ HERRÁN, José Manuel. 1987, "Construcción y sentido de Cuervo", Los Cuadernos del Norte, n. 4 (monográfico): Hitos y mitos en la Regenta, pp. $86-92$.

- 1990. "The structure and meaning of Cuervo" en AA. VV., "Malevolent insemination" and other essays on Clarin, edited by Noël Valis, Michigan Romance Studies, 1990.

GRANJEL, Mercedes. 1983. Pedro Felipe Monlau y la higiene española del siglo $X I X$, Salamanca, Universidad.

GULLON, Ricardo. 1952. "Las novelas-cortas de Clarín”, Insula, n” 76, Abril 1952, p. 3.

HUME, David. (1741) 1990. Essays Moral and Political, en Disertación sobre las pasiones y otros ensayos morales, ed. bilingüe, introducción, traducción y notas de José Luis Tasset Carmona, Barcelona, Anthropos.

— (1757) 1990. Four Dissertations, en Ibíd.

LAVATER, Jean Gaspard. 1781. Essai sur la physiognomonie. Destiné a faire connaître l' homme et à le faire aimer, La Haye.

LETOURNEAU, Charles. 1887. L'évolution de la morale, París, Delahaye Lacrosnier.

LISSORGUES, Yvan. 1983. "La sociología criminal y su influencia en los escritores españoles del fin de siglo", Révue de Littérature Comparée, tomo XLVIII, n. 1 pp. 12-32.

LUCEÑO Y BECERRA, Tomás. 1872. "El agente fúnebre", Los españoles de ogaño. Colección de tipos de costumbres dibujados a pluma, Madrid, Librería de V. Suárez, vol. I, pp. 158-163.

MARISTANY, Luis. 1973. El gabinete del doctor Lombroso (delincuencia y fin de siglo en España), Barcelona, Anagrama.

- 1983. "Lombroso y España: nuevas consideraciones", Anales de Literatura Española, Universidad de Alicante, nº 2, pp. 361-381.

MESONERO ROMANOS, Ramón de. 1851. "El duelo se despide en la Iglesia", Escenas matritenses, Madrid, Imp. y Lib. de Gaspar y Roig.

MONLAU, Pedro Felipe. 1846. Elementos de higiene privada, Barcelona, Imp. de Pablo Riera.

-(1847) 1871. Elementos de higiene pública o arte de conservar la salud de los pueblos, 3ํㅡㄹ edición, Madrid, Imp. M. Rivadeneyra, vol. I. 
OCHOA, Juan. 1893. "Un genio", La Justicia, 14 de Enero de 1893.

- 1898. Rodríguez Chanchullo (D. Próspero), Madrid Cómico, 18 de Febrero de 1898.

PÉREZ DE ALAYA, Ramón. 1943. "Clarín y Don Leopoldo Alas", en Clarín, Doña Berta, Cuervo, Superchería, Buenos Aires, Emecé Editores.

PESET, José Luis y Mariano. 1975. "Introducción, AA.VV., Lombroso y la escuela positivista italiana, Madrid, C.S.I.C, pp. 9-209.

RICHARDSON, José G. s.a. Arte de llegar a viejo. Medios de conseguirlo, Barcelona, Centro Editorial de La Vida Literaria.

RÍOS, Laura de los. 1965. Los cuentos de Clarín. Proyección de una vida, Madrid, Revista de Occidente.

ROMERO TOBAR, Leonardo. 1983. "Mesonero Romanos: entre costumbrismo y novela", Anales del Instituto de Estudios Madrileños, Madrid, C.S.I.C., tomo XX pp. 243-259.

RUBIO CREMADES, Enrique. 1983. "Costumbrismo y novela en la segunda mitad del siglo XIX", Anales de Literatura Española, Universidad de Alicante, $\mathrm{n}^{\circ} 2$, pp. $457-472$.

- 1988. "Colaboraciones costumbristas de los novelistas de la segunda mitad del siglo XIX", en AA.VV., Realismo y naturalismo en España en la segunda mitad del siglo XIX, Barcelona, Anthropos, pp. 146-157.

SOBEJANO, Gonzalo. 1985. "Leopoldo Alas, maestro de la novela corta y del cuento", Clarín en su obra ejemplar, Madrid, Castalia, pp. 77-114.

Mme de STAEL. (1796) 1818. De l'influence des passions sur le bonheur des individus et des nations, París, Maradan.

UNAMUNO, Miguel de. (1917) 1972. Abel Sánchez. Una historia de pasión, edición de José Luis Abellán, Madrid, Castalia. 